\title{
Embedded Control System for Recent Petrol Engine Control
}

\author{
M. Saravanan, J. Senthil, S.Sudhakar, L. Sathish Kumar, Ogirala Sowmithri
}

\begin{abstract}
In the current scenario of automotive industries, it is much challenging for the research and developers to develop updated engines/vehicles to satisfy the proposed demands of environmental policy levels. To achieve the expected demands of emissions coming out from an engine exhaust not only with the help of converters in the exhaust pipe line but also the emissions should be controlled during burning of fuel with air in the ignition chamber itself.

The controlled combustion of fuel and air requires not only the control fuel injection timing with duration of injection and tune up of the complete fuel injection system with hardware components of ECU but also requires the control of ignition timing. The complete electronic control for petrol engine with direct injection unit is required to communicate between PC and an engine. CAN with SPI interface is used to communicate the electronic control unit with engine
\end{abstract}

\section{Keywords : ECU,CAN,SPI,Controlled Combustion}

\section{INTRODUCTION}

In a traditional flash start motor, a homogeneous blend of fuel and air is provided. The burning in a vaporous fuel-air blend lighted by a sparkle which is portrayed by a quick advancement of a fire that starts from the purpose of start and spreads outwards in a consistent way.

At the point when burning is started by a flash, it is called controlled ignition and when ignition is started by a problem area, it is called uncontrolled ignition. Under ordinary burning conditions, the ignition is controlled and this is an originator's goal. Uncontrolled burning is related with pre-start and running on.

At the point when the fire spread proceeds as far as possible of the ignition chamber with no sudden change in its speed and shape, that burning is called as typical burning.

The ignition of fuel-air blend relies upon chain responses. To begin with, just a couple of profoundly dynamic constituents encompassing the start point cause responses. These thusly produce extra dynamic constituents to cause responses soon a point is reached where the chain breaking

Revised Manuscript Received on December 16, 2019

* Correspondence Author

M Saravanan*, Mechanical Engineering Department, Aarupadai Veedu Institute of Technology, Vinayaka Mission's Research Foundation, Deemed to be University. Email: saravanan@avit.ac.in

J.Senthil, Mechanical Engineering Department, Aarupadai Veedu Institute of Technology, Vinayaka Mission's Research Foundation, Deemed to be University.

S.Sudhakar, L.Sathish Kumar, Ogirala Sowmithri, UG Student, Mechanical Engineering Department, Aarupadai Veedu Institute of Technology, Vinayaka Mission's Research Foundation, Deemed to be University. reactions dominate the chain forming reactions.

\section{BASIC PRINCIPLES OF GDI SYSTEM}

\section{A. Basic concept}

In ordinary gas motors, scattering of an air-fuel blend with the perfect thickness around the flash attachment was troublesome. Nonetheless, this is conceivable in the GDI motor. Besides, incredibly low fuel utilization is accomplished in light of the perfect stratification empowers fuel infused delayed in the pressure stroke to keep up a very lean air-fuel blend.

\section{B. GDI combustion systems}

The right coordinating between injector highlights and in-chamber air movement is basic to achieve the ideal stratification, with the AFR required for start in the volume around the flash fitting hole, and at the hour of sparkle age. The ignition frameworks can be recognized relying upon the route used to acquire charge stratification. In this way, the accompanying grouping is conceivable:

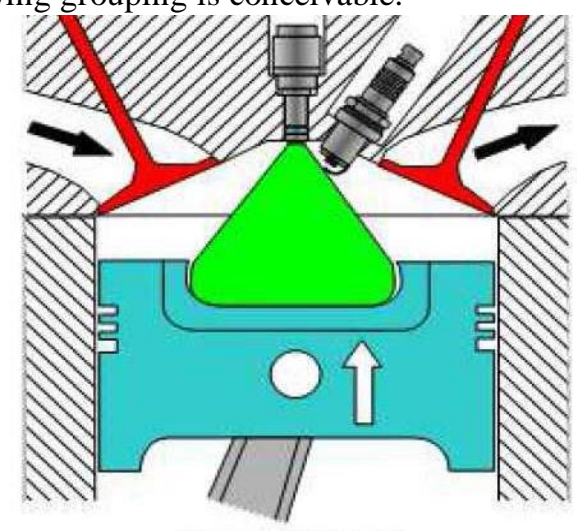

Fig. 1. Spray guided systems

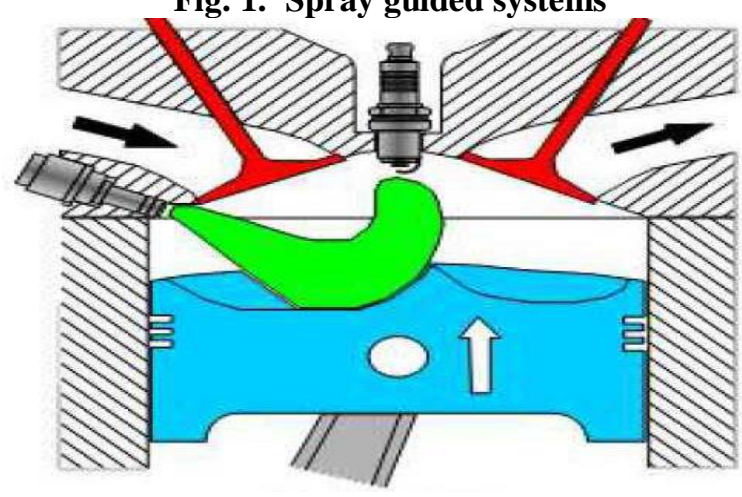

Fig. 2. Wall guided systems 


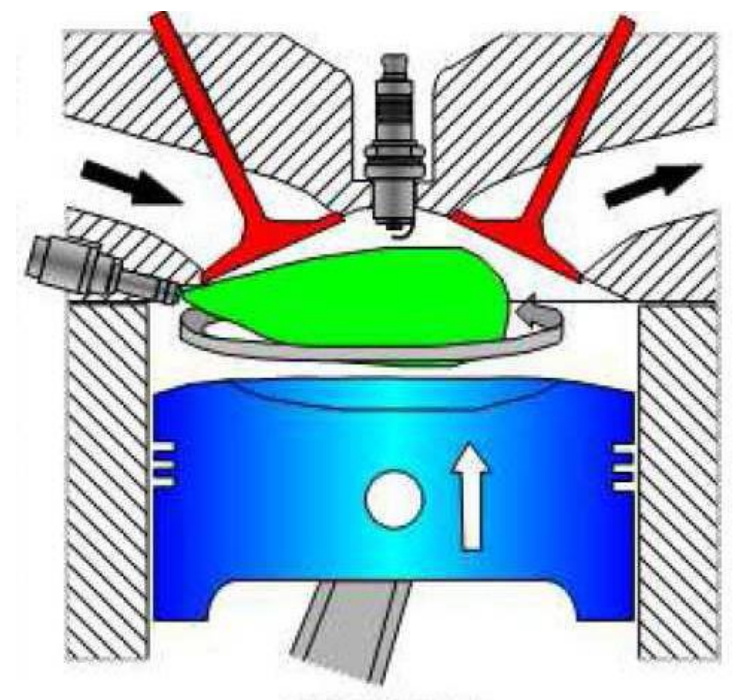

Fig. 3. Air guided systems

\section{Charge formation}

All Two essential charge modes, stratified and homogeneous charges are executed in GDI .

This stratified charge is encompassed for the most part via air and leftover gases, which gets the fuel and the fire far from the chamber dividers.

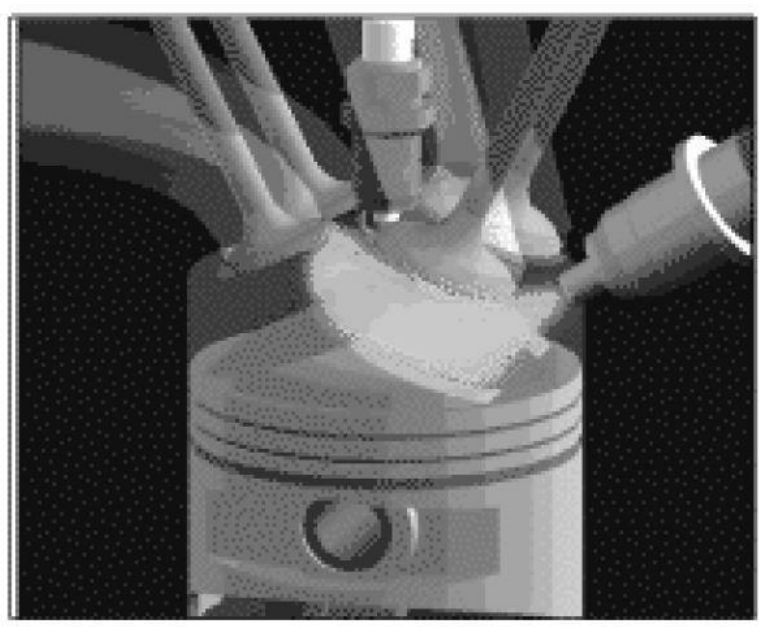

Fig. 4. Stratified mode

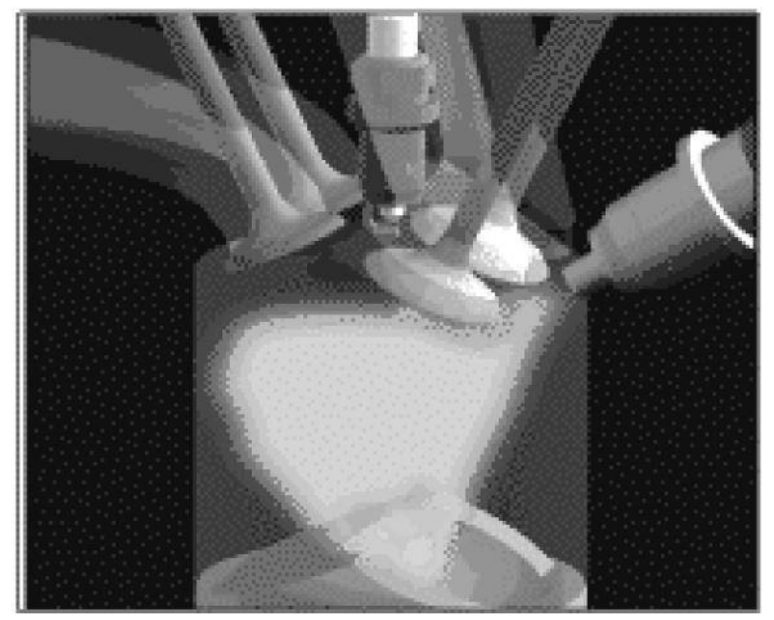

Fig. 5. Homogenous Mode

\section{Latest trends in combustion systems}

The Gasoline Injection -Stratified-Charged and Air-wall guided system is thought to be future of combustion systems.

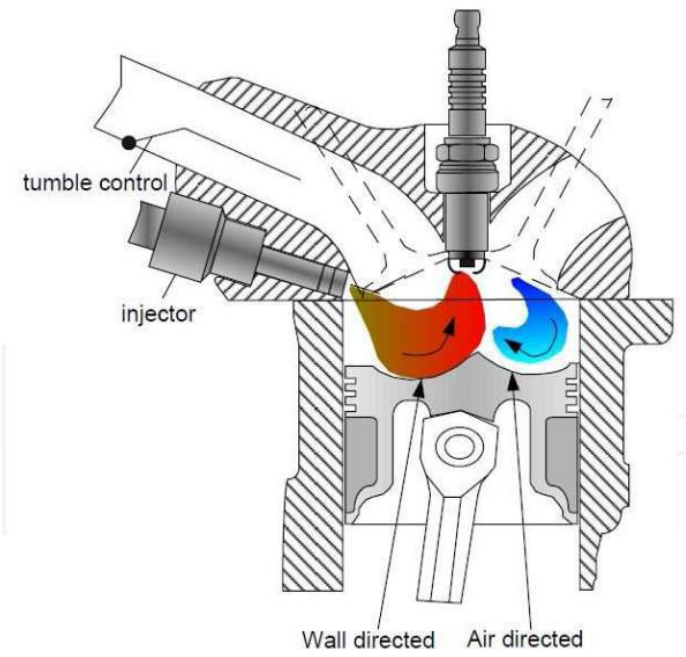

Fig. 6. Gasoline Injection -Stratified-Charged and Air-wall guided system

- During every pressure stroke, a progression of infusions is made divided just divisions of a second separated. This permits the better blend arrangement, ignition and lower fuel utilization.

- Air-divider guided start structure is a blend of air and divider consuming system. This structure is less delicate against the cyclic assortments of wind stream.

\section{E. Operating modes of GDI}

The different operating modes of GDI

- These motors have three essential working modes, stratified with a general lean blend, at low burden and speed, at medium burden and speed and at high burden and speed separately.

- High lean mode (stratified-charge) includes proportions as maximum as 65:1. These blends are a lot of more slender than regular blends and lessen fuel utilization. The fuel must be infused in a matter of seconds before the start, with the goal that the limited quantity of air-fuel blend is ideally put close to the sparkle plug. This system empowers the use of ultra-lean blends with extremely high air-fuel proportion which is inconceivable with customary carburetors or even port fuel infusion. In this mode NOx discharge is high so an EGR is utilized.

- At high burden, the blend in the stratified mode could be excessively rich, and in this manner ash can frame. At fast, it is difficult to give adequate stratification because of high disturbance in the chamber.

- Homogeneous mode is utilized for higher burden and speed run. It gets low outflows and high torque.

- As the fuel is infused during the admission stroke, there is adequate time for air-fuel blend arrangement.

- In this mode NOx outflow is exceptionally low so EGR isn't utilized.

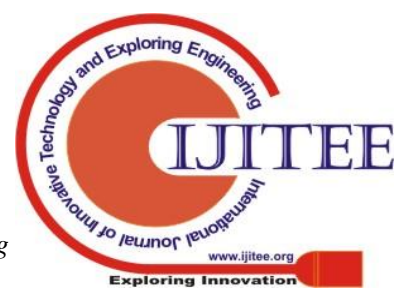


- Change from stratified mode to homogeneous mode happens in two phase infusion (twofold infusion) process .The essential infusion is performed at consumption stroke and lion's share of fuel is infused.

- The rest of the fuel is infused at (optional infusion) the finish of pressure stroke. Twofold infusion is made to diminish residue outflows and to diminish fuel utilization at low Motor rates.

\section{F. Emission standards}

Table- I: Bharath stage Emission standards for passengerees cars are listed below

\begin{tabular}{|c|c|c|c|c|c|}
\hline \multicolumn{6}{|c|}{ Bharath Stage Emission Standards GASOLINE } \\
\hline & & BSI & BS II & BS III & BS IV \\
\hline & & YEAR 2000 & YEAR 2005 & YEAR 2010 & YEAR 2017 \\
\hline HC & gkWhr & 1.1 & 1.1 & 0.66 & 0.46 \\
\hline NOx & gkWhr & 8.0 & 7.0 & 5.0 & 3.5 \\
\hline CO & gkWhr & 4.5 & 4.0 & 2.1 & 1.5 \\
\hline PM & gkWhr & 0.36 & 0.15 & 0.10 & 0.02 \\
\hline
\end{tabular}

\section{GDI REQUIREMENTS}

- Double injection strategy to control/reduce soot particles/PM emission with homogeneous lean mixture.

- High pressure fuel system with pressure ranges from 500-3000 Psi (35 - 206 bar) and a common rail.

- Modification of intake manifold to produce swirl / turbulence effect for better initial mixing (or) distribution of fuel.

- Modification of piston crown shape to achieve combined air-wall guided combustion system along with stratified charged direct injection.

- Along with 3-way catalytic converter, EGR system is used to store NOx when engine runs under lean mixtures, where NOx emission is high. Under rich mixtures, CO emission is high and this $\mathrm{CO}$ formed reacts with catalysts (additional) $\mathrm{Ca}$ and $\mathrm{Ba}$ to release the stored NOx and then reacts with $\mathrm{NOx}$ to form $\mathrm{CO} 2$ and $\mathrm{N} 2$. Thus converting NOx to N2. ECU with necessary/required sensors to control injection timings/start and stop of injection/Duel Pilot-main-Duel post fuel injection, lean and rich mixtures, ignition timing control, EGR Valve, Idling speed, etc.

- Any other fuel additives/catalysts for further reducing the emissions and to control knocking tendency. (Fuel Additives like MMT-Methyl cyclo-pentadienyl Manganese Tri-carbonyl etc, and Catalysts like - 3 way catalyst, Calcium, Barium etc,).

\section{EXPERIMENTAL PROCEDURE}

The following Kirloskar diesel engine is chosen for converting the GDI engine and their technical specifications were noted below:
Table- I: Technical Specifications of engines

\begin{tabular}{|c|c|c|}
\hline \multicolumn{3}{|c|}{ Engine Specifications } \\
& $\begin{array}{c}\text { KIRLOSKAR } \\
\text { OIL ENGINE }\end{array}$ & $\begin{array}{c}\text { PROPOSED GDI } \\
\text { ENGINE }\end{array}$ \\
\hline ENGINE TYPE & $\begin{array}{c}\text { VERTICAL, 4- } \\
\text { STROKE } \\
\text { DIESEL } \\
\text { ENGINE }\end{array}$ & $\begin{array}{c}\text { VERTICAL, 4- } \\
\text { STRE PETROL } \\
\text { GASOLINE } \\
\text { ENGINE }\end{array}$ \\
\hline NO.OF \\
CYLINDERS & 1 & 1 \\
\hline BORE & $80 \mathrm{~mm}$ & $80 \mathrm{~mm}$ \\
\hline STROKE & $110 \mathrm{~mm}$ & $110 \mathrm{~mm}$ \\
\hline $\begin{array}{c}\text { COMPRESSION } \\
\text { RATIO }\end{array}$ & $16.5: 1$ & $10: 1$ \\
\hline RATED SPEED & 1500 RPM & 1500 RPM \\
\hline COOLING TYPE & WATER & WATER \\
COOLING & COOLING \\
\hline
\end{tabular}

\section{RESULT AND DISCUSSION}

From the literature survey, it is concluded that a compression ratio of 10:1 is most suitable one in order to achieve reduced emissions and better engine performance. The proposed GDI engine is obtained by modifying the engine cylinder head with respect to positions of spark plug and injector for different combustion modes such as spray guided, air guided and wall guided combustion modes.

system level, function level, operation level, architecture level, and component level has been identified in our work.

At level 1, the specifications prescribed by the manufacturer are expressed in analytical terms. At the level 2, functions are deployed.

At operation level, functions are deployed by GDI. Highpressure fuel pump in a closed loop is controlled by an ECU.

Algorithm portrayed in a systematic (in any event executable) structure, regularly Simulink $\AA /$ State flow ${ }^{\circledR}$. At the design level, when an activity is com-mitted to a specific engineering, it delivers a product or equipment segment.

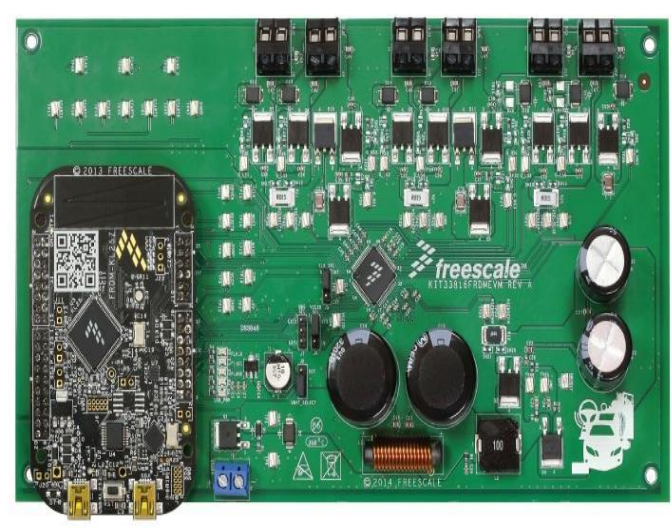

Fig. 7. DI engine Fuel Injection Driver Circuit. 
The above figure shows the Fuel Injection Driver circuit to control fuel injection timing with duration and fuel injection pressure. To control ignition timing, the ignition timing driver circuit was developed and the complete control unit is communicated between engine and PC. The CAN with SPI interface is chosen for communicating the control unit between $\mathrm{PC}$ with engine is as shown below.

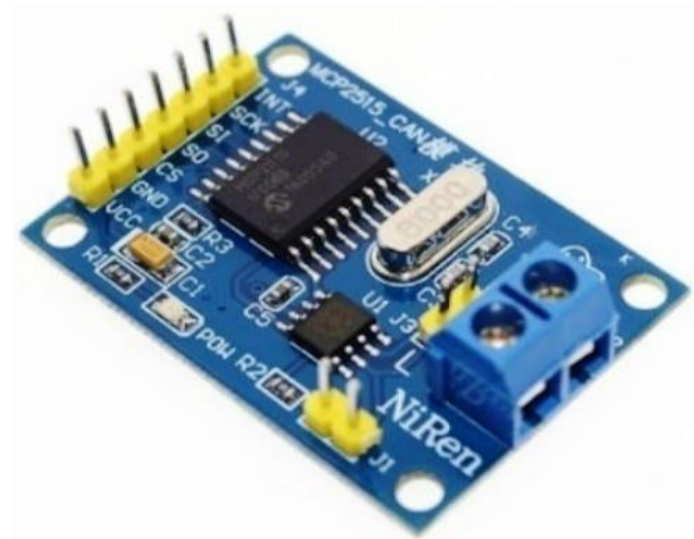

Fig. 8. CAN protocol interface for communication

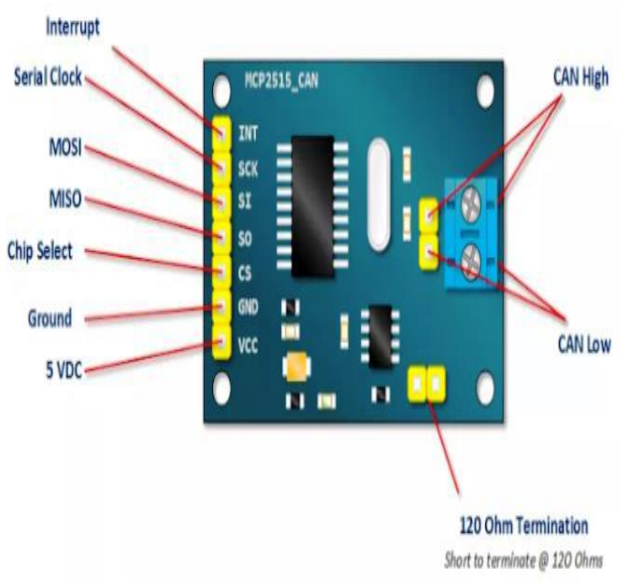

Fig. 9. SPI protocol interface for communication

\section{CONCLUSION}

In order to achieve EURO 6/BS IV emission norms, more power output and better fuel economy, GDI engine is proposed to be developed. In this project, the developed fuel injection driver circuit and ignition timing driver circuit is communicated between PC and an engine. CAN with SPI interface unit was used to communicate an electronic control unit with $\mathrm{PC}$ and an engine.

Further, the embedded codes will be developed for the entire control unit with communication interface and the engine will be operating with efficient electronic control such that the emissions from an engine exhaust will be within the limits.

\section{REFERENCES}

1. Köpple, F., Jochmann, P., Kufferath, A., and Bargende, M., "Investigation of the Parameters Influencing the Spray-Wall Interaction in a GDI Engine Prerequisite for the Prediction of Particulate Emissions by Numerical Simulation," SAE Int. J. Engines 6(2):911-925, 2013, doi:10.4271/2013-01-1089.

2. W.-K. M. Costa, U. Sorge, S. Merola, A. Irimescu, M. La Villetta, V. Rocco, "Split injection in a homogeneous stratified gasoline direct injection engine for high combustion efficiency and low pollutants emission", Italy, Energy, Elsvier, 117 (2016) 405-415.

3. Marilia Gabriela Justino Vaz, Jean Helder Marques Ribeiro, Felipe Grossi Lamas Amorim, Ramon Molina Valle, Rudolf Huebner, "Numerical Analysis of the Piston Crown Geometry Influence on the Tumble and Squish in a Single Cylinder Engine”, SAE International, 2014-36-0300.

4. B. Fabian Köpple, Paul Jochmann, Alexander Hettinger, and Andreas Kufferath - Robert Bosch GmbH, Michael Bargende - IVK, University of Stuttgart, "A Novel CFD Approach for an Improved Prediction of Particulate Emissions in GDI Engines by Considering the Spray-Cooling on the Piston", SAE International, 2015-01-0385.

5. E. Yang, J. and Anderson, R., "Fuel Injection Strategies to Increase Full-Load Torque Output of a Direct-Injection SI Engine," SAE Technical Paper 980495, 1998, doi: 10.4271/980495.

6. J. Wang, Shivakumar N, "Temperature Distribution Mearsurment on Combustion Chamber Surface of Diesel Engine - Experimental Method", International Journal of Automotive Science and Technology, 1(3), 8-11, 2587-0963.

\section{AUTHORS PROFILE}

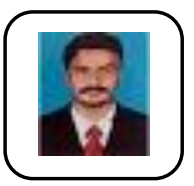

M.Saravanan, Assistant Professor, Mechanical Department, Aarupadai Veedu of Technology, Vinayaka Mission's Research Foundation, Deemed to be University. Having 8 years of experience. Life member in ISTE

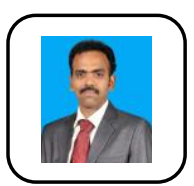

Second J Senthil Assoc. Prof., Department of Mechanical Engineering, Aarupadai Veedu Institute of Technology, Vinayaka Mission's Research Foundation, Deemed to be University. Having 13 years of experience. Life member in ISTE and MMS

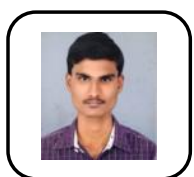

S.Sudhakar, UG Scholar, Department of Mechanical Engineering, Aarupadai Veedu Institute of Technology, Vinayaka Mission's Research Foundation, Deemed to be University.

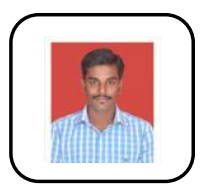

L.Sathish Kumar, UG Scholar, Department of Mechanical Engineering, Aarupadai Veedu Institute of Technology, Vinayaka Mission's Research Foundation, Deemed to be University.

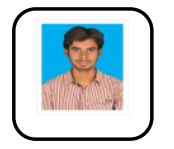

Ogirala Sowmithri profile UG Scholar,

Department of Mechanical Engineering, Aarupadai Veedu Institute of Technology, Vinayaka Mission's Research Foundation, Deemed to be University. 